\section{Important differences between sources of embryonic stem cells}

Sir-Stem-cell research, including the use of human embryonic stem cells, has important implications for medical practice in the future, and the relief of suffering in many serious and intractable diseases. The European Commission's European Group on Ethics in Science and New Technologies (EGE) has recently issued an opinion on the ethical aspects of human stem-cell research. As one of the two rapporteurs of this opinion, I was disappointed by your report "European panel rejects creation of human embryos for research" (Nature 408, 277; 2000)

Human embryonic stem cells, which can give rise to many different cell types and tissues, are derived from early embryos in vitro. Your report makes little attempt to distinguish between (1) embryos donated for research by patients undergoing in vitro fertilization (IVF) treatment ('spare embryos'); (2) embryos made for research by fertilizing donated oocytes in vitro ('research embryos') and (3) embryos made for research by transfer of somatic nuclei to donated oocytes ('nucleartransfer embryos').

The first category, spare embryos, covers all the human embryonic stem-cell lines at present being studied in the United States and Australia. The EGE concludes that in those countries (including the United Kingdom) where human embryo research is allowed, it is hard to see any specific argument that would prohibit extending the scope of such research in order to develop new treatments to cure severe diseases. Further, the group sees no argument for excluding funding of such research from the European Union's Framework programme. Thus it takes the view that, in Europe, the derivation of stem cells from IVF embryos should be not only publicly controlled but also publicly funded - unlike the situation in the United States, where state funding is not permitted to be used for this research.

The second category, research embryos, is deemed ethically unacceptable when spare embryos, including tens of thousands of frozen embryos in Europe which may become available for donation, represent a ready alternative source. The headline on your report is misleading, since the present EGE opinion deals only with stem-cell research, and does not consider the possible use of research embryos for projects that cannot by their nature be carried out on spare embryos.

For the third category, nuclear-transfer embryos, the group concludes that making such embryos would be premature at present, in view of the extensive research still to be done on embryonic stem cells derived from spare human embryos, as well as on fetal and adult stem cells. It is this third conclusion that apparently has led you to refer to a "dramatic twist" to the debate.

Nature has an excellent reputation for clarity of presentation of scientific and social issues. It is unfortunate that in this instance, when Parliament is about to give its considered opinion on whether to extend the purposes of human embryo research in the United Kingdom in order to develop new treatments for severe diseases, an article has appeared that engenders confusion rather than clarity. Anne McLaren

The Wellcome/CRC Institute, Tennis Court Road, Cambridge CB2 1QR, UK

\section{Weak euro hits PhDs too}

Sir - Your Careers and Recruitment report on Marie Curie fellowships (Nature 407, 427-429; 2000) raised the important issue of falling income among postdocs who are paid in euros but work in countries outside this currency region. We would like to draw attention also to $\mathrm{PhD}$ students in the same situation: they are usually less well paid than postdocs, but have similar expenses. Hence it is even more difficult for PhD students to cope with the sudden drop in value of the euro, particularly in the United States and United Kingdom.

As an example, scholarships from the Portuguese Foundation for Science and Technology (the main source of funding for Portuguese scientists) have a fixed value in euros regardless of the country in which the $\mathrm{PhD}$ student is working. Since the euro was introduced in January 1999, students in the United States and the United Kingdom have had to cope with a decrease in their income of $27.8 \%$ and $19.7 \%$, respectively.

We deeply regret that the authorities, although aware of the problem, oppose fixing the value of scholarships in the currency of the country in which the student is working. If measures are not taken to correct this unfairness, the mobility of students will soon be curtailed. Luis Graca ${ }^{\star}$, Susana Nery $\dagger$, Monica Bettencourt Dias $\ddagger$ Tiago Magalhaes $\S$ ${ }^{*}$ Sir William Dunn School of Pathology, University of Oxford, South Parks Road, Oxford OX1 3RE, UK †Skirball Institute, 540 First Avenue, New York, New York 10016, USA

$\$$ Department of Biochemistry and Molecular Biology, University College London, London WC1E 6BT, UK

§Department of Molecular Cell Biology, University of California at Berkeley, Berkeley, California 94720, USA

\section{Bernoulli was ahead of modern epidemiology}

Sir — The 300th anniversary year of Swiss mathematician Daniel Bernoulli's birth is an appropriate time to reveal that he was, by a long way, the first to express the proportion of susceptible individuals of an endemic infection in terms of the force of infection and life expectancy ${ }^{1}$.

His formula is valid for arbitrary agedependent host mortality, in contrast to some current formulas which underestimate herd immunity (one minus the proportion of susceptible individuals), the vaccination threshold that has to be exceeded to eliminate an infection and the basic reproduction number (the inverse of the proportion of susceptible individuals $)^{2}$.

Bernoulli's main objective was to calculate the adjusted life table if smallpox were to be eliminated as a cause of death. He clearly defined the two epidemiological parameters, which nowadays are called the force of infection $\lambda$ (the annual rate of acquiring an infection) and the case fatality $c$ (the proportion of infections resulting in death). If $L$ is life expectancy, then the proportion of susceptible individuals $u$ can be written as $u=r /(\lambda L)$, where $r$ is the cumulative incidence (the proportion of a cohort that will be infected). As the proportion $c$ of all infected individuals die, the proportion $q$ of all deaths due to smallpox is $q=c r$.

Hence Bernoulli estimated the susceptible proportion using the expression $u=q /(c \lambda L)$. From several large cities (especially London) which recorded cause-specific numbers of deaths, estimates of $q$ were known to be about $1 / 13=7.7 \%$. Bernoulli used Halley's life table for the city of Breslau and came up with the estimates $\lambda=1 / 8$ per year and $c=1 / 8=12.5 \%$. For Paris he assumed a life expectancy of 32 years which yields a proportion of susceptible individuals of $15 \%(=107,000 / 700,000)$, or a herd immunity of $85 \%$.

If one assumes a constant death rate (an exponentially distributed survival time), then $u=1 /(1+\lambda L)$ (ref. 3 ). This formula gives $80 \%$ as the estimate for herd immunity. The formula most frequently used today ${ }^{2}$ assumes a rectangular survival function in which all individuals live until a maximum age $L$. Then $u \approx 1 /(\lambda L)$, which gives only $75 \%$ for herd immunity. We therefore suggest that it is more accurate to use the more general formula derived by Bernoulli.

Jean le Rond d'Alembert, who had been in conflict with Bernoulli over several issues previously, violated the unwritten rules of the day by publishing a critique of Bernoulli's approach in 1761 (ref. 4), five 
years before Bernoulli's essay eventually appeared in print. Bernoulli's motivation to add this formula in the final version (prepared in 1765) was explicitly to show the superiority of his 'exact' approach over the crude estimate of d'Alembert, according to whom the proportion of susceptible individuals was "much less than half".

The reason why Bernoulli's important formula has escaped notice for so long may be its cryptic presentation: one has to recover it by substituting his numerical values with their general symbols. In formulating his laudable objectives, however, he is admirably clear: "I simply wish that, in a matter which so closely concerns the well-being of mankind, no decision shall be made without all the knowledge which a little analysis and calculation can provide."

Klaus Dietz ${ }^{\star}$, J. A. P. Heesterbeek $\dagger$

${ }^{*}$ Department of Medical Biometry, University of

Tübingen, 72070 Tübingen, Germany

†Centre for Biometry, PO Box 16, 6700 AA

Wageningen, The Netherlands

1. Bernoulli, D. Mém. Math. Phys. Acad. R. Sci. Paris 1-45 (1766); English translation by Bradley, L. in Smallpox Inoculation: An Eighteenth Century Mathematical Controversy (Adult Education Department, Nottingham, 1971).

2. Anderson, R. M. \& May, R. M. Infectious Diseases of HumansDynamics and Control (Oxford University Press, Oxford, 1991).

Dietz, K. Stat. Meth. Med. Res. 2, 23-41 (1993).

4. D’Alembert, J. Opuscules Mathématiques, t. II (Paris, David, 1761).

\section{Aquaculture: part of the problem, not a solution}

Sir-Aquaculture is claimed to aid the production of large quantities of low-cost protein-rich food to help feed the world, and to diminish pressure on ocean fisheries. In our opinion, neither of these claims is justified.

First, except in some parts of Asia, the main purpose of aquaculture has been to produce a luxury product for those who can afford to pay high prices. Second, Naylor et al. ${ }^{1}$ analysed the consequences of aquaculture practices and indicated that the growth of global production of farmed fish and shellfish will not relieve pressure on ocean fisheries.

Naylor et al. also indicated that aquaculture can diminish world fisheries indirectly by habitat modification, collection of wild seedstock, food-web interaction, nutrient pollution and the introduction of exotic species. However, in this last factor the authors referred only to possible hybridization between farm escapees and wild populations of Atlantic salmon, and to the spreading of pathogens. We believe it is also necessary to consider other consequences of introducing nonindigenous organisms, such as the elimination of autochthonous species by altering food webs, competition, hybridization and so on.

For scientists in developing countries such as ourselves, this point is of great importance. We would like to call to the attention of international organizations such as the World Bank, the International Development Bank and the Food and Agriculture Organization (FAO) the need to stop promoting aquaculture as a means of obtaining income from exports, and to concentrate on producing food for poor people. These organizations should stop promoting technological packages using exotic species and instead help the development of culture technologies for native species with the potential for aquaculture.

To give some examples: the FAO approved a technical cooperation project in Venezuela to genetically improve red tilapia, an unnecessary waste of resources that was a total failure ${ }^{2}$. The International Development Bank is partially financing a programme to culture exotic species in Panama, including the scallops Argopecten purpuratus, the cachamas Colossoma macropomus and Piaractus brachipomus, the channel catfish Ictalurus punctatus, the Sergeant or Peacock bass cichlid Cichla ocellaris, the giant prawn Macrobrachium rosenbergii and the bullfrog Rana catesbiana.

The World Bank finances several programmes in Latin America (see http://www.worldbank.org) introducing species such as Litopenaeus vannamei and L. stylirostris into countries where they do not occur naturally. In one Honduran project, the World Bank claims there is no risk of introducing alien species because the shrimps L. vannamei and L. stylirostris occur naturally there, in the Gulf of Fonseca. But it does not mention the risk of introducing alien species in a Venezuelan project which also uses L. vannamei, although they are not native to that region.

Aquaculture can make unique contributions to world nutrition, thanks to its extremely high productivity in many situations and to the fact that aquatic crops are primarily protein rather than starch. Certain aquatic organisms may be better at converting primary foods than ruminants, fowl or even pigs. Some, such as filterfeeding fishes and molluscs, feed on microscopic plankton that cannot be used directly for human food.

However, if the aquaculture industry is going to reduce the pressure on wild fish stocks and provide food for the world's growing population, substantial changes must be made by governments, the private sector and international funding agencies. They must protect coastal ecosystems; promote research and development of native species; and encourage farming of low-trophic-level fish - those low on the food chain. International technical funding agencies can exert great influence in changing practices. Otherwise, as Naylor et al. point out, an expanded aquaculture industry poses a threat, not only to ocean fisheries, but also to itself.

Julio E. Pérez ${ }^{\star}$, Mauro Nirchio $\dagger$, Juan A. Gomez

${ }^{*}$ Instituto Oceanografico, Universidad de Oriente,

Cumaná, Venezuela

$\dagger$ Escuela de Ciencias Aplicadas del Mar,

Universidad de Oriente, Isla de Margarita,

Venezuela

$¥$ Centro de Ciencias del Mar y Limnológia,

Universidad de Panamá, Panamá

1. Naylor, R. L. et al. Nature 405, 1017-1024 (2000).

2. Perez, J. E., Gomez, A. \& Nirchio, M. Interciencia 24, 321-323 (1999).

3. Programa de Modernización de Servicios Agropecuarios. Componente Acuicultura (Inter-American Development Bank, Panamá, 1995). http://www.iadb.org/EXR/doc98/ apr/lcpanaq.htm

\section{Funding would prevent waste of research time}

Sir - It has become clear over the last decade that doing research in Spain is quite a heroic task (see, for example, Nature 407, $428 \& 941 ; 2000)$. Poor funding and lack of prospects for young researchers are among the many obstacles that have precluded the rise of Spanish science to the very top. Although an increase in the amount of money devoted to research is an obvious prerequisite, the many problems that young investigators face haven't been analysed in detail.

A numerical comparison with our EU counterparts (not to mention with the United States and Japan) shows the need to create positions to absorb many of the excellently trained postdocs that Spain has sent abroad during the past 15 years. But nobody is discussing the conditions under which these new hirings should take place. The fact is that Spain has no policy of providing start-up packages for the newly hired group leaders. This has unfortunate consequences, as new researchers sit in their offices (if they have offices) and begin chasing grants for a period of up to three years, losing all continuity with their research projects.

If Spain is to have a core of young investigators doing science at its best, these scientists should be provided not just with positions but also with funding for research. Otherwise, talent is wasted, again. Pedro Martínez

Department of Anatomy and Cell Biology, University of Bergen, Aarstadveien 19,

5009 Bergen, Norway 